\title{
Politeness markers in English for business purposes textbook
}

\author{
Alemi, Minoo $\triangle$ \\ Sharif University of Technology, Tehran, Iran (alemi@sharif.ir) \\ Razzaghi, Sajedeh \\ Sharif University of Technology, Tehran, Iran (sajedeh_razzaghi@yahoo.com)
}

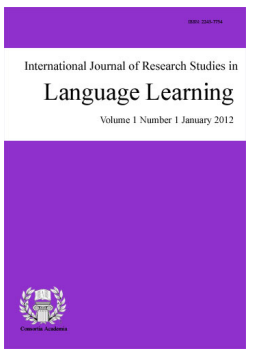

ISSN: 2243-7754 Online ISSN: 2243-7762

OPEN ACCESS

\section{Abstract}

The inadequacy of research studies in evaluating ESP textbooks in terms of politeness markers in business communication cannot be neglected. To this end, the present study aimed to investigate the politeness markers based on House and Kasper's (1981) politeness structure taxonomy in the spoken discourse of the ESP textbook entitled Business Result in order to find a pattern of these politeness markers in business conversations. The overall findings of the present study revealed that according to House and Kasper's (1981) taxonomy of politeness structures, the intermediate level of the Business Result textbook suffers from the inadequate inclusion of politeness structures categorized by this taxonomy. Due to limited amount of politeness structures in this ESP textbook in order to attenuate or compensate the unwelcome impact of any face threatening acts (FTAs), the ESP learners may encounter serious difficulties in developing a comprehensive communicative competence in the business setting. The lack of this pragmatic input especially in ESP textbooks in which the learners are to master the English in order to be able to communicate in an international business context can lead to inappropriate development of communicative competence which may eventually result in more serious financial or economic losses.

Keywords: ESP textbook evaluation; business textbook; politeness markers; business result; House and Kasper's politeness structure taxonomy 


\section{Politeness markers in English for business purposes textbook}

\section{Introduction}

English for Specific Purpose (ESP) is now one of the most important movements in the field of TEFL/TESOL. Over the past few years, the ESP experts attempted to provide an appropriate design for the developing of ESP courses in order to meet the professional communicative needs of the students. Most of the studies on the development of foreign language (FL) knowledge have revealed that simply focusing on the forms of language at the expense of its functions may lead to mere mastery of the grammar and vocabulary of the language but incomplete knowledge of pragmatic uses of the language (Crandall \& Basturkmen, 2004; Judd, 1999). As the goal of language teaching is to develop communicatively competent learners, therefore teaching practice as well as teaching materials must concentrate on developing not only the structure of the language but also its sociolinguistic and pragmatic rules. "While a grammar error when performing an impositive face-threatening speech act may be seen as a language problem by native speakers, an error of appropriacy may characterize the non-native speakers as being rude and offensive" (Uso-Juan, 2007, p. 208). In this case an ESP text book should be designed in a way that reflects a holistic view of the language.

One of the relevant issues in interlanguage pragmatic is the concept of face and politeness which relates to FTA (face threatening act). Attention to these concepts is one of the key successes to any business relationships. According to Brown and Levinson (1978, cited in Bousfield, 2008), "face is something that is emotionally invested and that can be lost, maintained or enhanced"(p. 35). "Face consists of two related elements; namely positive face and negative face: Positive face is an individual's desire to be liked, approved of, respected and appreciated by others; negative face is an individual's desire not to be impeded or put upon, to have the freedom to act as one chooses" (Thomas, 1995, p. 169). According to Renkema (1993 cited in Null, 2008) "five possible strategies for performing FTAs were outlined according to their relative degree of face threat which, in turn, may reflect the degree of politeness: 'Do the FTA on record without redressive actions (the least polite)'; 'Do the FTA on record with redressive actions addressing positive face'; 'Do the FTA off record'; 'Don't do the FTA' (the most polite strategy)" (p. 79).

According to Louhiala-Salmenin and Kankaanranta (2010) the number of business professionals increases the importance of having a comprehensive knowledge of English as a lingua franca becomes outstandingly central in business contexts. In this case, following the politeness strategies will uniquely attribute to the performance of successful co-operative social interaction. Complying with the politeness strategies and the correct use of them can have a great impact in the success of business interactions as it minimizes any conflict and confrontation that may result from linguistic or cultural mismatches.

The inadequacy of research studies in evaluating ESP textbooks in terms of politeness markers is something that cannot be neglected. No one can deny the importance of the concept of politeness in the area of business communication and that increases the need for conducting studies in this domain. The present study tries to investigate the politeness markers in the spoken discourse of the ESP text book titled Business Result in order to find a pattern of these politeness markers in business conversations.

\section{Related review of literature}

Neither teaching nor learning is possible without the use of relevant textbooks. As the demands for business English has increased, a considerable amount of English textbooks for business purpose has been designed and published. For these ESP books to meet the real world professional demands of the learners, they must be designed based on some criteria, one of the most important of which is they should provide situations in which the learners will be encountered in their business life. In this case the ESP experts should first design a detailed 
need analysis survey which indicates the competence gap in specific area, and the required level of knowledge alongside the ways of achieving it (Wisniewska, 2011). The other important criterion of ESP books is that they should provide learners with various language skills and strategies which they will potentially use in their professional encounters in the real world. This magnifies the need to conduct research on evaluating English for business purpose textbooks. The importance of English for business purposes have been captured by so many research studies which focus on different aspects of these ESP textbooks. According to Nickerson (2005, cited in Louhiala-Salmenin \& Kankaanranta, 2010) "there are two distinct trends in the research of English for the Specific Business Purposes. First, there has been a discursive turn; a shift from the analysis of isolated business texts to the analysis of the contextualized communication (e.g., Porcini, 2004) and second, the focus has moved from language skills to language strategies, i.e. identification of strategies that make the communicative event successful irrespective of the mother tongue of the English speakers" (e.g., Planken, 2005) (p. 204).

In the study of Louhiala-Salminen, Charles, and Kankaanranta (2005) both trends were followed. A communication survey and an analysis of both spoken and written genre were used as a means of data collection from two merger Finish-Swedish companies: "The result of the study indicated that typical communicative patterns of Finish and Swedish were more complicated in authentic meeting and email discourse" (Louhiala-Salminen \& Kankaanranta, 2010, p. 205). One of the main strategies in any types of communications is politeness strategy. In any communication the interactants need to achieve satisfactory social interactions. In order to reach these social and communicative goals, people should know some basic concepts such as respecting, protecting and valuing each other's face (Hernandez-Flores, 2004). But according to Bousfield (2008), at the same time, each individual wants to save and protect his/her face as well (cf. Chen, 2001; Meier, 1995; Watts, 1992). Therefore, people select some communicative strategies to provide a balance between their face and that of their interlocutors. These strategies are of utmost importance in a business communication because violating them may lead to misunderstanding and conflict on the part of the business interlocutors, which eventually may lead to a great economical loss. In this case an enormous number of studies have been conducted in the English for business purposes area regarding different communicative strategies in both written and spoken discourse in order to provide a clear picture of the learners' needs.

An example of research on communicative strategies is the one carried out by Vinagre (2006). She explored how utilizing politeness strategies by collaborative email partners could help them overcome the potential threat to each other's negative face. Eleven students and their partners, who were studying English and Spanish respectively, participated in the study. Their introductory email exchanges had been analyzed in terms of the politeness strategies. The findings revealed that contrary to the author's expectation, the participants rarely used negative politeness strategies, but instead they used a considerable amount of positive strategies especially those relating to "claiming common ground", 'assuming or asserting reciprocity' and 'conveying cooperation', and the use of these strategies suggested that the partners seek solidarity, closeness and cohesion (Vinagre, 2006).

Another study conducted by Nall (2004), investigated a collection of 12 emails sent by Chinese vendors to a U.S company. The study utilized Brown and Levinson's (1978) politeness guideline to analyze the FTA strategies used by these Chinese vendors. The findings revealed that the Chinese vendors showed a different attitude toward FTA and maintaining business relationship which was not in line with Brown and Levinson's (1978) model. The study proposed that utilizing authentic business writings and clarifying differences in textual factors are the necessary components of any EFL/ESL teaching business corresponding.

According to Huh (2006), a great number of researches have been done on business including the analysis of business written discourse, communication skills and strategies (Barbara, Celini, Collins, \& Scott, 1996; Charles, 1996; Chew, 2005; Eustance, 1996; Gimenez, 2000, 2001, 2002, 2006; Grosse, 2005; Louhiala-Salminen, 1996, 2002; Nickerson, 2005; St. John, 1996). A range of studies have been conducted in business English area focusing on English as a lingua franca in international business contexts (Louhiala-Salminen, Charles, \& Kankaanranta, 2005; Nikerson, 2005; Planken, 2005; Rogerson-Revell, in press). Genre analysis research on business writing (Akar, 2002; Bhatia, 1993; Eustance, 1996; Gains, 1999; Gimenez, 2000, 2002, 2005; Jenkins 
Alemi, M. \& Razzaghi, S.

\& Hinds, 1987; Santos, 2002) with the focus on corresponding (letters and emails) investigates the cultural and linguistic aspects of a particular discourse community.

A number of studies have been conducted on the spoken business discourse (Chakorn, 2004). Hasan (1977) has investigated the steps in appointment making and categorized them in a transactional order as the greeting being the first step with the following steps of query, identification, application, offer, confirmation, documentation, and the summary as the last step of this chain. Another research carried out by Dow (1989) concentrates on some features of spoken discourse in a simulated business negotiation in English. He uses two groups of Australian students of business English and one group of Austrian marketing professionals in order to compare their negotiation performances. The findings suggest that the students have problems understanding the ritual interchange such as compliment and invitation, and in contrast provide many tactical threats such as over-aggression and over compliancy (Chakorn, 2004).

Mulholland (1997) examines the nature of request in business spoken discourse between two groups of western and eastern representatives. She analyses the acts of making, hearing and acknowledging request in order to reach those cultural differences that cause misunderstanding and break down in business communication. The result reveals that eastern groups indicate few differences in their professional and private talk, which is not the case for western representatives. She concludes that forming request is totally culture specific and it can be even different within one culture, so paying attention to these cultural diversities will lead to more fruitful business relationships (Chakorn, 2004).

A number of researches on business communication skills and strategies (Brbara et al., 1996; Chew, 2005; De Beaugrande, 2000; Louhiala-Salminen, 1996; St. John, 1996) focused on the frequent business communication skills and strategies. Another series of research conducted on discourse analysis of business communication (Charles, 1996; De Beaugrande, 2000; Gimenez, 2001; Louhiala-Salminen, 2002; Louhiala-Salminen et al., 2005) with the focus on discourse patterns of the most frequent business communication tasks; namely business negotiation and meeting. The result of the discourse analysis of business communication discovered two points, first, it indicated the discourse patterns related to specific tasks, second, it also revealed the influential factors of these discourse patterns including, degree of formality, cross-cultural aspects and business relationship characteristics (Huh, 2006).

The present study tries to examine the politeness markers as the communicative strategies in the spoken business discourse in an ESP textbook titled 'Business Result' in order to discover a pattern in business spoken genre. The study tries to answer the following research question:

$>$ What is the pattern of politeness markers in the intermediate series of the ESP textbook titled Business Result?

\section{Methodology}

\subsection{Instrument}

The present study utilized two instruments. One is an ESP textbook titled Business Result (Hughes \& Naunton, 2007). The textbook series has been published in three levels of elementary, intermediate and upper intermediate, and they were published by Oxford University Press. The focus of this study is on the intermediate level of these series. The text- book consists of sixteen units, no dialogue is presented in the units; therefore, the focus of this study is on the overall 45 listening conversation transcripts which were included in the units.

The other instrument is the taxonomy of politeness structure proposed by House and Kasper (1981) which includes eleven categories as follows:

1. Politeness markers, by which they mean expressions added to the utterance to 'show deference to the 
addressee and to bid for cooperative behavior'. The most obvious example of a politeness marker in English is please, but there are others, e.g., if you wouldn't/don't mind, tag questions with the modal verb will/would following an imperative structure (Close the door, will you/would you?), etc.

2. Play-downs, by which they understand syntactic devices which 'tone down the perlocutionary effect an utterance is likely to have on the addressee'. These are then subdivided into five subcategories which in fact boil down to the following four: use of the past tense (I wondered if . . , I thought you might . . .), progressive aspect together with past tense (I was wondering whether . ., I was thinking you might ...), an interrogative containing a modal verb (would it be a good idea . ., could we ...), a negative interrogative containing a modal verb (wouldn't it be a good idea if . .., couldn't you ....).

3. Consultative devices, by which they understand structures which seek to involve the addressee and bid for her/his cooperation, e.g., Would you mind . . , Could you . . .

4. Hedges, by which they understand the avoidance of giving a precise propositional content and leaving an option open to the addressee to impose her/his own intent, e.g., kind of, sort of, somehow, more or less, rather, and what have you.

5. Understaters, which is a means of underrepresenting the propositional content of the utterance by a phrase functioning as an adverbial modifier or also by an adverb itself, e.g., a bit, a little bit, a second, a moment, briefly.

6. Downtoners, which 'modulate the impact' of the speaker's utterance, e.g., just, simply, possibly, perhaps, really.

7. Committers, which lower the degree to which the speaker commits her/himself to the propositional content of the utterance, e.g., I think, I believe, I guess, in my opinion.

8. Forewarning, which is a strategy that could be realized by a wide range of different structures in which the speaker makes some kind of metacomment on an FTA (e.g., pays a compliment) or invokes a generally accepted principle which s/he is about to flout, etc. (e.g., far be it from me to criticize, but . . ., you may find this a bit boring, but ..., you're good at solving computer problems).

9. Hesitators, which are pauses filled with non-lexical phonetic material, e.g., er, uhh, ah, or are instances of stuttering.

10. Scope-staters, which express a subjective opinion about the state of affairs referred to in the proposition, e.g., I'm afraid you're in my seat, I'm disappointed that you couldn't . ., it was a shame you didn't...

11. Agent avoiders, which refer to propositional utterances in which the agent is suppressed or impersonalized, thereby deflecting the criticism from the addressee to some generalized agent, e.g., passive structures or utterances such as people don't do $X$.

This taxonomy has been used as a framework of our analysis. Each of these 45 listening comprehension transcripts in Business Result textbook has been analyzed on the basis of these categories. In order to facilitate understanding we gave each politeness structure a code. Politeness markers (PM), play-downs (PD), consultative devices (CD), hedges (H), understaters (UN), downtoners (D), committers (C), forewarnings (F), hesitators (HS), scope-staters (S) and agent avoiders (A). The data was gathered from the 45 listening conversation transcripts which were presented at the end of the book. The frequency analysis was used to investigate the number and the type of each politeness structure. The goal is to present a pattern of politeness markers in this ESP textbook. 


\section{Results}

Table 1 indicates the analysis of the frequencies of the politeness structures, each politeness structure as coded before is presented in the row and the letter $\mathrm{C}$ in the left column of the table represents the number of conversations, as we analyzed 45 conversations, each of them are numbered and listed in the table.

Table 1

Frequency of politeness markers

\begin{tabular}{|c|c|c|c|c|c|c|c|c|c|c|c|}
\hline & PM & PD & $\mathrm{CD}$ & $\mathrm{H}$ & $\mathrm{U}$ & $\mathrm{D}$ & $\mathrm{C}$ & $\mathrm{F}$ & HS & $\mathrm{S}$ & $\mathrm{A}$ \\
\hline $\mathrm{C} 1$ & & & & & & & & & 5 & & \\
\hline $\mathrm{C} 2$ & 1 & & & & 1 & 1 & 2 & & 3 & & \\
\hline C3 & & & & & & 2 & 1 & & 2 & & \\
\hline $\mathrm{C} 4$ & & & & 1 & & 2 & & & 4 & & \\
\hline C5 & & & 2 & & 1 & 4 & & & 11 & & \\
\hline C6 & & & & 2 & & 4 & & & 5 & & \\
\hline C7 & & & & 2 & & 1 & 1 & & 2 & & \\
\hline C8 & & & & 2 & 2 & 8 & 1 & & 5 & & \\
\hline C9 & & & & & & & & & 2 & 1 & \\
\hline C10 & & & 1 & 1 & & 4 & & & 2 & & \\
\hline C11 & & & & 1 & & & 1 & 2 & 3 & & \\
\hline C12 & 1 & & 3 & 3 & 1 & 2 & 1 & & 3 & & \\
\hline C13 & & & 1 & & & 4 & & & & 1 & \\
\hline $\mathrm{C} 14$ & & & 1 & 1 & 2 & 1 & & & 6 & & \\
\hline C15 & & & 2 & 2 & & 1 & 1 & & 5 & & \\
\hline C16 & & 1 & & & 1 & & 1 & & 4 & & \\
\hline C17 & 1 & & & & & & & & & & \\
\hline C18 & & & 1 & & 2 & 2 & & & 1 & 2 & \\
\hline C19 & 1 & 1 & & 1 & & 1 & 2 & 1 & 4 & & \\
\hline C20 & & & & & & 2 & & & 6 & & \\
\hline $\mathrm{C} 21$ & & & & & 1 & 4 & 1 & & 1 & & \\
\hline $\mathrm{C} 22$ & & & 4 & 1 & 1 & 1 & 1 & & 1 & & \\
\hline $\mathrm{C} 23$ & & & 1 & 1 & 1 & & 1 & & 2 & & \\
\hline $\mathrm{C} 24$ & & & & 1 & & 3 & 3 & & 3 & 1 & \\
\hline $\mathrm{C} 25$ & & & & & & 1 & & & 3 & & \\
\hline C26 & & & & 1 & & & & & 2 & & \\
\hline $\mathrm{C} 27$ & & & & 1 & & & & & & & \\
\hline C28 & & & & & & & 1 & & & & \\
\hline C29 & & & & & & & 1 & & 1 & 1 & \\
\hline C30 & 1 & & & & & 1 & 3 & & & & \\
\hline C31 & & & & 1 & 2 & 2 & & & 1 & & \\
\hline C32 & & & & & 1 & & & & 1 & & \\
\hline C33 & & & & 2 & & 1 & 1 & & 2 & & \\
\hline C34 & & & 1 & & & & 1 & & & & \\
\hline C35 & & & & & 3 & & 1 & & 4 & & \\
\hline C36 & & & & & & 2 & & & 2 & & \\
\hline C37 & & & 1 & 1 & & & & & & & \\
\hline C38 & & & 2 & & 1 & & & & & 1 & \\
\hline C39 & & 1 & & 1 & & & & & 3 & 1 & \\
\hline $\mathrm{C} 40$ & & & & 1 & 2 & 1 & 3 & & 3 & & \\
\hline C41 & & & & & & & 1 & & 1 & & \\
\hline $\mathrm{C} 42$ & & & & 1 & 2 & 2 & & & 1 & & \\
\hline C43 & & & & & & 1 & 1 & & & & \\
\hline C44 & & & & & 1 & 1 & 2 & 1 & 5 & & \\
\hline $\mathrm{C} 45$ & & & & 2 & 2 & 1 & 2 & & 4 & & \\
\hline Total & 5 & 3 & 20 & 30 & 27 & 60 & 34 & 4 & 113 & 8 & 0 \\
\hline
\end{tabular}

As can be seen in the above table there is a wide difference in terms of the varieties and frequencies of the politeness structures in the conversations. A total of 304 politeness structures were used in 45 listening 
conversations of the Business Result text book. Out of these, 5 were politeness markers, 3 were play-downs, 20 were samples of consultative devices, 30 were hedges, 27 were samples of understaters, and 60 downtoners, 34 committers, 4 forewarnings, 113 hesitators, and 8 scope-staters were found in the conversations. No samples of the agent avoiders structure were found.

Table 2

Frequency of occurrence politeness markers and examples

\begin{tabular}{|c|c|c|c|}
\hline $\begin{array}{l}\text { Politeness } \\
\text { markers }\end{array}$ & $1.6 \%$ & I'll hang on to it if you don't mind. & Let's look at the last two, shall we? \\
\hline Play-down & $0.9 \%$ & $\begin{array}{l}\text { I was wondering if you were still } \\
\text { interested in my company's proposals. }\end{array}$ & Can we arrange a meeting on Sunday? \\
\hline $\begin{array}{l}\text { Consultative } \\
\text { devices }\end{array}$ & $6.5 \%$ & Could you check it out for me? & $\begin{array}{l}\text { Will you hold while I contact the } \\
\text { warehouse? }\end{array}$ \\
\hline Hedges & $9.8 \%$ & $\begin{array}{c}\text { Make it a kind of place you like to } \\
\text { work in... }\end{array}$ & ....I have some sort of say. \\
\hline Understaters & $8.8 \%$ & $\begin{array}{c}\text { A bit traditional, buy they’ve } \\
\text { always.... }\end{array}$ & Wait a moment,... \\
\hline Downtoners & $19.7 \%$ & But I really need a change... & I just can’t do it. \\
\hline Committers & $11.1 \%$ & I think we should address this point .... & $\begin{array}{l}\text { I don't think we can reach the } \\
\text { decision, .. }\end{array}$ \\
\hline Forewarnings & $1.3 \%$ & $\begin{array}{l}\text { It might seem a bit difficult to use, but } \\
\text { in fact it is very simple }\end{array}$ & I was finding it a little difficult.... \\
\hline Hesitators & $37.1 \%$ & Mm, yeah, absolutely & Er,...,not really \\
\hline Scope-staters & $2.6 \%$ & $\begin{array}{c}\text { Do we have to swipe every time we } \\
\text { want to go through the door? I'm } \\
\text { afraid so,... }\end{array}$ & $\begin{array}{l}\text { But it's a shame that we can't meet } \\
\text { soon.... }\end{array}$ \\
\hline Agent avoiders & $0 \%$ & no & no \\
\hline
\end{tabular}

In order to better understand the findings, we will deal with each of these 11 politeness strategies employed in the conversations. The first politeness structures are politeness markers which were used 5 times in the whole 45 conversations. The following is an example:

(1) Jacinta: Here, let me take your coat.

Marvin: Uh, that's ok; I'll hang on to it if you don't mind

Here the expression of "if you don't mind" shows that the addressee expresses his deference to the addresser's offer, rather than baldly rejects it.

Or in the second example:

(2) Dr Mayer: Oh I'm sorry, I thought....well...

Hitoshi: Please don't apologize. I am proud of my Japanese heritage.

"Please" is an important feature of politeness markers which adds courteousness to the utterance. In the above example omission of it can lead to a completely impolite sentence and shows that the girl (Hitoshi) looks offended.

The second politeness structure as categorized by House and Kasper (1981) is play-down which is only found in 3 out of 45 conversations.

(3) Karl: Well, I was wondering if you were still interested in my company's proposals?

Anton: Yes, I am..... 
Alemi, M. \& Razzaghi, S.

In this example Karl used one of the four subcategories of play-downs; progressive aspect together with past tense, in order to mitigate the perlocutionary effect that his utterance may have on Anton. Or in the fourth example:

(4) Sergio: Can we move the meeting back to Thursday?

Elena: Ok...yes...

Here Sergio toned down the potential inconvenience that he may cause for Elena by changing the meeting's day.

The third politeness structure is consultative device, 20 samples of which are found in the conversations.

(5) C: Sorry, but I don't quite understand how they work. Can you tell us more about them?

A: Mm. when you come to the door.............

Here the addresser uses the structure of can you in order to politely engage the addressee and asks him for more information.

The fourth politeness structure is hedges which are one of the most frequent politeness strategies used to mitigate the negative force of the utterances. 30 samples of them were found in the conversations of this textbook.

(6) A: How do you mean?

B: Well, why not try to make the company you work for a bit more up to date? Make it the kind of place you really want to work in....

(7) Stella: ......I'm always happier carrying out decision in which I have some sort of say.

(8) Traveler: .... I guess we'll eat out somewhere......

In all of the above examples the addressers or the addressees avoid giving precise answers and leave options for their interlocutors to express their own ideas and by using these hedges they attenuate the potential unwelcome effects of their utterances.

The fifth structures are understates, 27 of which were found in the conversations.

(9) Gisele: two weeks ago? Wait a moment, how did they send it?

Linda: they said they'd sent it by sea

(10) Interviewer: .....or will there be time for pleasure?

Traveler: Well, a little bit of both, I hope....

As it was shown in the above examples, they are used to tone down the propositional content of the utterance and can have the form of adverbs or adverbial modifiers (House \& Kasper, 1981).

The second most frequent politeness structures in the listening conversations of the Business Result are down-toners. 60 samples of them are found to be used in the conversations.

(11) Harriet: ........ just wonder if she'll cope with that...

(12) A: ......but the current situation as it stands, simply doesn't prevent people from entering your office. 
(13) Gisele: Thanks. I really want to know what's happened to it.

According to these examples, the speakers try to adjust and modify the impact of their utterances on the listeners by using the above downtoners, and the omission of them will make these sentences bald imperatives which are not appropriate in these contexts.

34 samples of committers as the seventh politeness structures categorized in House and Kasper (1981) taxonomy were used in the conversations.

(14) Linda: ....you said ASAP, which I guess is by courier.

(15) Patrick:.... I think we should wait and see who else is moving there.

In these two examples it is clear that the speakers turn down the degree of his/her commitment to the content of the utterance.

Four samples of forewarnings found in the conversations of this book.

(16) Olli: Well, on the whole, I was impressed with the welcome Mr. Rahman gave me, but I think we're wasting our time with them.

In this example Olli tried to redress the unwelcome effect of his utterance by starting with a compliment about Mr. Rahman's welcoming manner.

The most frequent politeness structures found in the conversations of this textbook were hesitators. As House and Kasper (1981) put forward, hesitators are pauses that are filled with non-lexical phonetic materials.

(17) Samira: good idea. Do you know where it is?

Josie: Er...not really

Here used a kind of hesitators to express his uncertainty of the effect of his utterance.

The tenth politeness structures were scope-staters which soften the negative force of the utterance as in this example:

(18) B: do you mean that we have to swipe every time we want to go through a door?

A: I'm afraid so, but the current situation, .......

The addressee used the expression of I'm afraid rather than the direct response of Yes, in order to lower the potential negative effect of his/her utterance.

And the last politeness structure is agent avoiders which were not found in any of the 45 conversations of the book and according to House and Kasper (1981) have the role of deflecting the criticism from the addressees to some generalized agent. The analysis conducted here on the use of politeness markers in business conversations reveals that in most conversational situations, hesitators were the most frequent politeness structures (with the frequency of 113) employed in the conversations of this textbook, which express some degrees of speaker's uncertainty of the effects of his/her utterances. Besides, the agent avoiders which were not found in any of the conversations; play-downs were the least frequent politeness structures, utilized in the conversations in this textbook.

\section{Discussion}

This study tried to highlight the inclusion of politeness structures in the listening conversations of the ESP 
Alemi, M. \& Razzaghi, S.

text book of Business Result, an intermediate level. We made use of House and Kasper's (1981) politeness structure taxonomy as a model for analyzing the number and types of politeness structures in the 45 listening conversations of the above mentioned book. After analyzing 45 listening conversations, the total of 304 politeness structures were found in this textbook. Ten out of eleven politeness structures stated in House and Kasper (1981) taxonomy; namely, politeness markers, play-downs, consultative devices, hedges, understaters, downtoners, committers, forewarnings, hesitators, scope-staters which were found to be used with varying degrees, but agent avoiders was not found in any of the listening transcript. The overall findings reveal the inadequate inclusion of politeness markers in the listening conversation of the intermediate level of the Business Result textbook.

The most frequent politeness strategy found to be hesitators. In fact, out of 304 politeness structures $37.1 \%$ were hesitators. This strategy which is a very important strategy in conversations expresses the uncertainty and hesitation of a speaker in what to say next or how to express his/her utterance. By using hesitators speakers try to buy time for them in order to manage what to say next and at the same time keep their turns. In the case of business conversations in which business persons try to keep their relations with each other and also reach their business goals and benefits, the use of hesitators can be really crucial. For instance, in the below extract in which two partners are checking the responses of an applicant to decide whether she is appropriate for their job position the hesitation of Conrad to express his agreement was clear. By using hesitators of "Um" he had some time to think for his answer and also keeps his floor to add the next sentence in which he did not completely reject the application:

Harriet: and six? She puts agree. Maybe she has problems trusting her colleagues. I'm not too happy about that.

Conrad: Um. Me neither. I think we should address this point in the interview.

The importance of this strategy seems to be neglected in most spoken conversations (Lindsay \& O'Connell, 1995; McCarthy, 1998). But this inherent characteristic of the conversations is also neglected in the intermediate level of Business Result textbook.

Downtoners as the second most frequent politeness strategy of this textbook was found in $19.1 \%$ of the whole 45 conversations. Downtoners are those modality markers used to tone down the impact the utterance may have on the hearers. As in any native/nonnative business communication the parties involved try to scale down the potential unwelcome effects their utterances may have on their interlocutors. By utilizing this strategy, they can avoid any face threatening act that may be the result of cultural misunderstandings or unawareness, and in this case, they can save their business relationships. Regarding the use of downtoners in conversations, it can be stated that Business Result textbook does not comprehensively reflect this point in the listening conversations.

Out of 304 politeness structures $11.1 \%$ was found to be committers. The use of this prevalent strategy in business communication can indicate that the speakers try to reduce the degree of their commitment and express their points of view, ideas, understandings and they politely give some space to their business interlocutors to state their opinions and perceptions. The insufficient inclusion of this strategy in the listening conversations can be mentioned as another weak point of this ESP textbook in terms of politeness structures. Hedges as one of the important politeness strategies can be utilized as a means of attenuating the illocutionary forces of request or direct questions. The speakers use hedges such as sort of, kind of, somehow, etc. in order to express politeness by lowering the precision of their utterance. Utilizing hedges in a business context can express politeness by softening the impact of the utterances.

A: ....she'll report the incident and you just have to wait for further instructions. Does that make sense?

B: Kind of, but could you explain the first part again.... 
In the above example the speaker's use of kind of indicates his/her inexact representation of his/ her understanding. His/her next sentence reveals that he/she did not understand the first part of speaker A's explanation and he/she used kind of in order to avoid precise answer and in this case speaker A is warned against drawing any specific implication about her perception. This common and useful strategy was inadequately $(9.8 \%)$ included in the conversations.

Understaters as another important politeness structure can be used in business communication in order to mitigate the force of an utterance by means of understatements such as a bit, a little, for a moment, etc.

Appraiser: ....I received lots of good reports about your hard work

Chris: Oh, good. That's nice to hear. I was finding it all a little difficult when I first came to work here....

In the above example, Chris tried to tone down the impact of his utterance (difficulty of his job situation) by using an understater of a little. This structure should be included sufficiently in the business conversations, but only $8.8 \%$ of them were included in the listening conversations.

Another important but less frequent structure was consultative devices which are utilized in order to politely ask for the interlocutors' cooperation. In a business context where parties always doing business activities, the use of the structures such as can you, would you, would you mind, etc. can be used excessively in different business transactions and relations. As most of the selected listening conversations were dialogues such as meetings and telephone conversations in which the interlocutors requesting for information, regarding the use of politeness structures the insufficient use of committers can be noticed as another weak point of this book.

Out of 304 politeness structures only $2.6 \%$ were samples of scope-staters. These structures are utilized in order to express a personal opinion about the state of affairs related to the issue.

Anton: ....we won't be able to give you a date at this stage.

Karl: I understand. These things happen, but it's a shame that we can't meet soon.......

In the above extract the use of a scope-stater of it's a shame that expresses the personal attitude of Karl about Anton's negative response to his offer. This politeness structure can be really useful in business communications in which the speaker tries to maintain the business relationship by politely express his/her point of view. This strategy should be sufficiently included in the business communications of the English for business purposes textbooks.

Politeness markers as one of the commonest politeness strategies are used to show respect to the interlocutor and politely ask for his/her cooperation. According to House and Kasper (1981) please is the most salient example of this category. This modifier is used to soften the imposition of an utterance and courteously ask for cooperative behavior. Out of 45 conversations only one please was found. Regarding the frequent use of please in most business transactions and relations, the inadequate inclusion of it can be considered as a shortcoming of this textbook in terms of the use of politeness structures.

Another politeness structure is forewarnings which are used to redress the potential face threatening acts performed by interlocutors by complimenting or invoking a generally accepted rule which they want to violate. As in any native/nonnative business communication disagreement or conflict may occur, the business persons can resort to this strategy in order to compensate any positional FTA which may be caused as a result of this agreement or conflict. The lack of this type of input (1.3\%) can lead to inappropriate development of pragmatic competence.

Play-downs are those politeness structures that are utilized in order to attenuate the perlocutionary negative 
Alemi, M. \& Razzaghi, S.

effect of an utterance on the hearer. House and Kasper (1981) divided these structures into four categories of: past tense (I wondered if..), progressive aspect with past tense (I was wondering if...), an interrogative containing a modal verb (would it be a good idea....) and a negative interrogative with a modal verb (couldn't you...).in terms of politeness structures, Only $0.9 \%$ of this strategy was found in the conversations which can express another shortcoming of this ESP textbook.

The absence of agent-avoiders as the eleventh structure in House and Kasper (1981) taxonomy can be viewed as another problem of this book in terms of the inclusion of the politeness strategies. These structures can mitigate the effect of the utterances by removing the criticism from the addressee to some general agent. In the case of business communication the interlocutors can indirectly criticize the inappropriacy of any business-related issue by using this strategy while saving his interlocutors' face.

The overall findings of the present study reveal that according to House and Kasper's (1981) taxonomy of politeness structures, the intermediate level of the Business Result textbook suffers from the inadequate inclusion of politeness structures categorized by this taxonomy. Due to limited amount of politeness structures in this ESP textbook in order to attenuate or compensate the unwelcome impact of any FTAs, the ESP learners may encounter serious difficulties in developing a comprehensive communicative competence in the business setting. The lack of this pragmatic input especially in ESP textbooks in which the learners are to master the English in order to be able to communicate in an international business context can lead to inappropriate development of communicative competence which may eventually result in more serious financial or economic losses.

\section{Conclusion}

Along with the expanding of the global economic system, the appeal for communicating across cultures is increasing. According to Louhiala-Salminen (2002) and Taillefer (2007) approximately 70\% of business communication takes place with non-native partners, this result reveals the importance of knowing the cultural context of each partner in order to succeed in communication. It is a truism that the success of any intercultural business activity depends on the effectiveness of the cross-cultural communication among the business persons. The abilities of the business persons to appreciate the cross-cultural differences and adjust themselves to foreign cultures are the elements that can lead them to a more fruitful communication. Politeness as one of the most important constituents of social interaction can act as a mediator which can minimize interpersonal frictions and establish rapport and management. Mishandling business communications, either by ignoring the nuance of social considerations in the other business persons or employing inappropriate amount of politeness, can result in interpersonal disturbance or finally leads to failure in business transactions. In this case a culturally profound and comprehensive textbook can provide a good cultural insight for the learners of that specific language.

As the focus of our study was on the analysis of the ESP textbook, we tried to shed light on the importance of one of the main aspects of successful communication; namely politeness strategies, which should be highly considered as a vital point in any communication especially in business communication neglecting of which will lead to misunderstanding, communication breakdown, serious financial or economic losses. In this case evaluating ESP textbooks is an important phenomenon and it is helpful for teachers because textbooks are one of the main resources for teaching and learning and can be affected by many factors such as teachers' approaches, instructional situations, students' preferences and other environmental factors.

The current study carries with it two main practical implications. The first implication is for the business textbook developers who are responsible for writing and developing textbooks' materials which can benefit their users and can be considered as a main informational resource for them. It is obvious that culture and language are inseparable, understanding what people say requires a comprehensive knowledge of the cultural contexts and cultural mechanisms working within those contexts. Culture in conjunction with personality patterns of individuals can form the communicative styles of its members (Isik, 2003). Having an appropriate knowledge of the culture of the target language is a must for the learners. In this case material and textbook developers must 
comprehensively include in their materials and textbooks, an appropriate amount of the knowledge of the culture of the target language. This point will be more vital for ESP textbooks and material designers as the ESP learners need to develop a communicative competence in cross-cultural business contexts and if they could not gain this competency they would face with a lot of communicational deficiencies and conflicts. As a result the task of textbook and material developers is very demanding and challenging as they should write textbooks and materials which are highly rich in both language and cultural aspects, and can explicitly address the needs of its learners. The findings of this study can help them to develop materials that can portray the complex nature of cross-cultural communication.

The second implication is for ESP teachers (especially business as it was the focus of this study) who use ESP textbooks and materials as their main source in teaching. Teachers should highlight the cultural and pragmatic aspects of the target language. They should utilize appropriate learning instructions that can bring cultural and pragmatic points into the learners' attention. Teachers should not ignore or downgrade the culture of the target language; in contrast, they should emphasize the cultural points and try to teach explicitly or implicitly the cultural differences and similarities between the target language and the learners' native language. Politeness strategies as the main aspect of cross-cultural communication and as the significant factors in intercultural business communication should be explained and addressed by the teachers, and also the teachers need to teach how, when, and why these politeness strategies can be appropriately used.

The present study was focused on politeness markers in a business textbook, but further studies need to be conducted on the frequency of different speech acts in business textbooks to discover if they meet the requirements of the business communication in different situations.

\section{References:}

Akar, D. (2002). The macro contextual factors shaping business discourse: The Turkish case. International Review of Applied Linguistics in Language Teaching, 40, 305-322. http://dx.doi.org/10.1515/iral.2002.015

Barbara, L., Celani, A., Collins, H., \& Scott, M. (1996). A survey of communicative patterns in the Brazilian business context. English for Specific Purposes, 15, 57-71. http://dx.doi.org/10.1016/0889-4906(95)00026-7

Bhatia, K. (1993). Analyzing genre: Language use in professional settings. Harlow: Longman.

Bousfield, D. (2008). Impoliteness in interaction. Amsterdam. Philadelphia: John Benjamins.

Brown, P., \& Levinson, S. (1987). Politeness: Some universal in language usage. Cambridge: Cambridge University Press.

Chakorn, O. (2004). A synthesis of discourse analysis and contrastive rhetoric and their application to research on business discourse. NID Language and Communication Journal, 9, 19-49.

Charles, M. (1996). Business negotiation: Interdependence between discourse and the business relationship. English for Specific Purposes, 15, 19-36. http://dx.doi.org/10.1016/0889-4906(95)00029-1

Chen, R. (2001). Self politeness: A proposal. Journal of Pragmatics, 33, 87-106. http://dx.doi.org/10.1016/S0378-2166(99)00124-1

Chew, K. (2005). An investigation of the English language skills used by new entrants in banks in Hong Kong. English for Specific Purposes, 24, 423-435. http://dx.doi.org/10.1016/j.esp.2005.02.004

De Beaugrande, R. (2000). User-friendly communication skills in the teaching and learning of business English. English for Specific Purposes, 19, 331-349. http://dx.doi.org/10.1016/S0889-4906(98)00031-3

Dow, E. G. (1989). An analysis of features of spoken discourse in a stimulated business negotiation: A comparison between Innsbruck Sowi-Spranchenzentrum students and Swarovski marketing specialists. Unpublished Masteral thesis. England: University of Birmingham.

Eustace, G. (1996). Business writing: Some aspects of current practice. English for Specific Purposes, 15, 53-56. http://dx.doi.org/10.1016/0889-4906(95)00025-9

Gains, J. (1999). Electronic mail: A new style of communication or just a new medium? An investigation into the 
Alemi, M. \& Razzaghi, S.

text features of email. English for Specific Purposes, 18, 81-101. http://dx.doi.org/10.1016/S0889-4906(97)00051-3

Gimenez, J. (2000). Business email communication: some emerging tendencies in register. English for Specific Purposes, 19, 237-251. http://dx.doi.org/10.1016/S0889-4906(98)00030-1

Gimenez, J. (2001). Ethnographic observations in cross-cultural business negotiations between non-native speakers of English: An exploratory study. English for Specific Purposes, 20, 169-193. http://dx.doi.org/10.1016/S0889-4906(99)00038-1

Gimenez, J. (2002). New media and conflicting realities in multinational corporate communication: A case study. International Review of Applied Linguistics in Language Teaching, 40, 323-334. http://dx.doi.org/10.1515/iral.2002.016

Gimenez, J. (2006). Embede business emails: Meeting new demands in international business communication. English for Specific Purposes, 25, 154-172. http://dx.doi.org/10.1016/j.esp.2005.04.005

Grosse, C. (2004). English business communication needs of Mexican executives in a distance-learning class. Business Communication Quarterly, 67, 7-23. http://dx.doi.org/10.1177/1080569903261840

Hasan, R. (1977). Text in the systemic-functional model. In W.U. Dressler (Ed.), Current trends in textlinguistics: Research in text theory 2 (pp. 228-46). Berlin: Walter de Gruyter.

Hernandez-Flores, N. (2004). Politeness as face enhancement. An analysis of Spanish conversation between friends and family. In R. Marquez Reiter \& M. E. Placenci (Eds.), Current trends in the pragmatics of Spanish (pp. 265-284). Amsterdam. Philadelphia: John Benjamins Publishing Company.

House, J., \& Kasper, G. (1981). Politeness markers in English and German. In F. Coulmas (Ed.), Conversational routine (pp. 157-186). Berlin: De Gruyter Mouton.

Hughes,J., \& Naunton J. (2007).Business result(Intermediate). Hungray: Oxford University Press.

Huh, S. (2006). A task-based need analysis for a business English course. Second Language Studies, 24, 1-64.

Jenkins, S., \& Hinds, J. (1987). Business letter writing: English, French and Japanese. TESOL Quarterly, 25, 327-349. http://dx.doi.org/10.2307/3586738

Louhiala-Salmenin, L. (1996). The business communication classroom vs. reality: What should we teach today? English for Specific Purposes, 15, 37-51. http://dx.doi.org/10.1016/0889-4906(95)00024-0

Louhiala-Salmenin, L. (2002). The fly's perspective: Discourse in the daily routine of a business manager. English for Specific Purposes, 21, 211-231. http://dx.doi.org/10.1016/S0889-4906(00)00036-3

Louhiala-Salmenin, L., \& Kankaanranta, A. (2010). English? Oh it's just a work: A study of BELF users' perceptions. English for Specific Purposes, 29, 204-209. http://dx.doi.org/10.1016/j.esp.2009.06.004

Louhiala-Salmenin, L., Charles, M., \& Kankaanranta, A. (2005). English as a lingua franca in Nordic corporate mergers: Two case companies. English for Specific Purposes, 24, 401-421. http://dx.doi.org/10.1016/j.esp.2005.02.003

Meier, A. J. (1995). Passages of politeness. Journal of Pragmatics, 24, 381-392. http://dx.doi.org/10.1016/0378-2166(94)00053-H

Mulholland, J. (1997). The Asian connection: Business request and acknowledgments. In F. Bargiela-Chiappini \& S. Harris (Eds.), The language of business: An international perspective (pp. 94-114). Edinburgh: Edinburgh University Press.

Nall, Sh. P. (2004). An analysis of the face threatening act strategies used in international trade email correspondence. National Symposium on Teaching English for Business Purposes HKU Proceedings, $78-100$.

Nickerson, C. (2005). English as a lingua franca in international business contexts. English for Specific Purpose, 24, 367-380. http://dx.doi.org/10.1016/j.esp.2005.02.001

Planken, B. (2005). Managing rapport in lingua franca sales negotiations: A comparison of professional and aspiring negotiators. English for Specific Purposes, 24, 381-400. http://dx.doi.org/10.1016/j.esp.2005.02.002

Porcini, G. (2002). Investigating discourse at business meetings with multicultural participation. International Review of Applied Linguistics in Language Teaching, 40, 345-373.

Renkema, J. (1993). Discourse studies an introductory textbook. Philadelphia: John Benjamins Publishing 
Company.

Rogerson-Revell, P. (In Press). Using English for international business: a European case study. English for Specific Purposes.

Santos, V. B. M. P. (2006). Genre analysis of business letters of negotiation. English for Specific Purposes, 21, 167-199. http://dx.doi.org/10.1016/S0889-4906(00)00028-4

St. John, M. (1996). Business is booming: Business English in the 1990s. English for Specific Purposes, 15, 3-18. http://dx.doi.org/10.1016/0889-4906(95)00023-2

Thomas, J. (1995). Meaning in interaction. London: Longman.

Uso-Juan, E. (2007). The presentation and practice of the communicative act of requesting in textbooks: Focusing on modifiers. In E. A. Soler \& M. P. S. Jorda (Eds.), Intercultural language use and language learning (pp. 223-243). The Netherlands: Springer. http://dx.doi.org/10.1007/978-1-4020-5639-0_12

Vinagre, M. (2006). Politeness strategies in collaborative email exchanges. Computer and Education, 50, 1022-1036. http://dx.doi.org/10.1016/j.compedu.2006.10.002

Watts, R. J. (1992). Linguistic politeness and politic verbal behavior. In R. J. Watts, S. Ide, \& K. Ehlich (Eds.), Politeness in language: Studies in its history, theory and practice (pp. 43-69). Berlin and New York: Mounten de Gruyter. 
Alemi, M. \& Razzaghi, S. 